\title{
Visualidad y diseño de comunicación visual, relación cartografías mentales-entorno en la definición de variables de diseño de comunicación visual
}

\begin{abstract}
Resumen
Este texto de carácter reflexivo plantea una revisión de la situación del diseño de comunicación visual frente a las dinámicas culturales y espaciales dictadas por las interacciones entre seres humanos y sistemas de naturaleza material. Fenómeno esta vez revisado desde la necesidad que tiene el diseño como actividad proyectual de naturaleza iterativa, de racionalizar los procesos de construcción de imaginarios individuales y colectivos para garantizar la configuración de relatos visuales con la potencialidad de actuar como elementos mediadores en el entorno.
\end{abstract}

Se plantea entonces una revisión de elementos conceptuales que ayudan a comprender la necesidad de plantear instrumentos para la recolección de variables sensibles en la relación de afectación entorno-individuo.

\author{
Juan Alejandro López \\ Carmona \\ Magíster en Diseño y Creación \\ Interactiva \\ Docente Fundación Universitaria \\ Bellas Artes \\ Medellín, Colombia \\ Correo electrónico: Investigacion \\ diseno@bellasartesmed.edu.co \\ ำ orcid.org/0000-0003-0024-9036 \\ Google Scholar
}

Recibido: Noviembre 6 de 2017 Aprobado: Agosto 17 de 2018

Palabras clave:

Cartografía mental, comunicación visual, cultura visual, diseño, sinestesia. 


\section{Visuality and visual communication design, mental mapping - environment relationship, in the definition of variables of visual communication design}

\begin{abstract}
This reflective text proposes a revision of the situation of visual communication design in front of cultural and spatial dynamics dictated by the interactions between human beings and natural material systems. This phenomenon is this time reviewed from the need of design as a project activity of iterative nature, of rationalization of the construction processes of individual and collective imaginaries to ensure the configuration of visual stories with the potential to act as mediating elements in the environment.
\end{abstract}

A review of conceptual elements that help to understand the need to suggest instruments for the collection of sensitive variables in the environment-individual relationship affectation is then proposed.
Key words:

Design; mental mapping; synesthesia; visual

communication; visual culture. 
Introducción: percepción e interpretación

\section{Imágenes}

Para comenzar el abordaje de este texto es prudente hablar de los elementos que se convierten en el sustrato fundamental de la construcción de imágenes y que serán entonces las variables perceptuales capturadas del mundo sensible, los fragmentos protagonistas cuando se trata de la interpretación y construcción que posteriormente integran las modelizaciones de la realidad o las imitaciones del mundo sensible tal como son definidas por Justo Villafañe en su texto Introducción a la teoría de la imagen de 1985.

También es conveniente dejar claro que para el abordaje de reflexiones relacionadas con la comunicación visual, los estímulos que se tienen en cuenta son aquellos susceptibles de convertirse en información de carácter visual; información perceptible mediante el ojo humano. Sin embargo, gracias a fenómenos como la sinestesia, otros sentidos como el olfato o el oído pueden estar asociados en la representación mental con datos recogidos mediante los órganos de la visión.

En primer lugar, cabe establecer la diferencia entre una imagen y una representación icónica dado que la primera ha de ser entendida como una modelización, una imitación del mundo, una reconstrucción o una simulación. En ese mismo orden de ideas, una imagen puede estar configurada por aquello que se observa mientras se tienen los ojos abiertos o por un recuerdo de la niñez en el que se ven vinculadas otras experiencias como el sabor de un helado o la textura del pasto donde se jugaba.

Por su parte las representaciones icónicas, aun siendo consideradas imágenes, se limitan a una apariencia visual sensible; una imitación con unos parámetros 
claros que desde Villafañe (1985) se determinan como hechos irreductibles de las imágenes icónicas: "1. Una selección de la realidad, 2. Unos elementos configurantes y 3. Una sintaxis" (p. 22). En cuanto al primer hecho es necesario señalar que cualquier imagen icónica obedece a una interpretación espaciotemporal; es decir que toda imagen tiene un tiempo y un espacio, así como un referente que le da origen — mismo que puede ser un fenómeno concreto o el resultado de la relación entre varios fenómenos-.

En segundo lugar, al hablar de los elementos configurantes, se puede señalar que una de las condiciones que separan este tipo de otras imágenes es que se trata de toda información sensible, susceptible de ser experimentada; bien se trate de fenómenos como el punto, la línea, el plano, el color y la textura (Wong, 1991). Finalmente, al hablar de la sintaxis se hace referencia a las relaciones e interacciones entre los diferentes elementos de una imagen; es decir la manera como se escribe esta imagen para determinar ciertas intencionalidades o efectos visuales (Acaso, 2011).

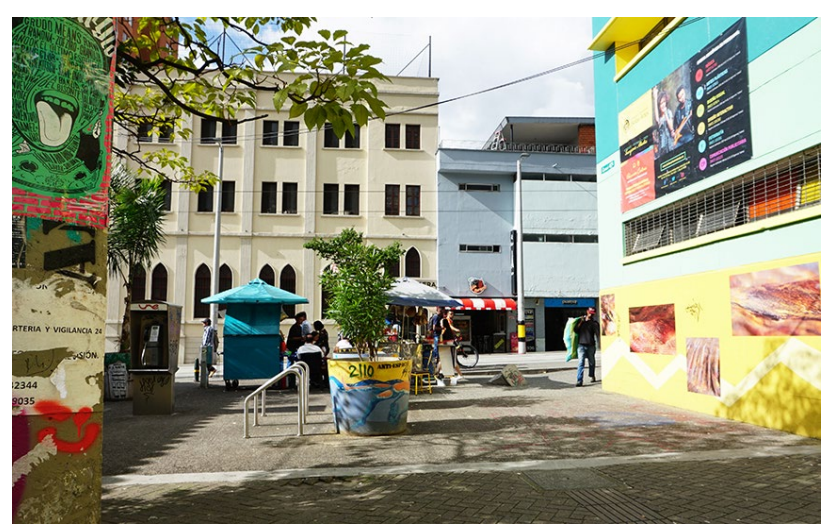

Figura 1. Pasaje cervantes, Medellín (2018). Fuente: fotografía por parte del autor. 
En la figura 1 es posible determinar con facilidad cuales son los hechos irreductibles que permiten catalogarla como una imagen icónica. En primer lugar se establece que se trata de la captura de un instante particular en un espacio específico, así como la representación de una serie de fenómenos que se dan en ese lugar (vendedores ambulantes, kioscos, elementos gráficos entre otros). En cuanto a los elementos configurantes pueden ser apreciados en esta imagen principalmente por los efectos de la luz y el color, así como de la simulación de profundidad. Finalmente existe una sintaxis que permite establecer una relación de orden semántico gracias al distanciamiento entre los elementos, así como lecturas de orden simbólico o interpretaciones sinestésicas (al asumir, por ejemplo, que el aparente brillo de la luz se asocia con un día cálido).

En este sentido puede afirmarse que una imagen será cualquier modelización de la realidad con independencia de su materialidad, como una imagen mental o una ensoñación; mientras que una imagen icónica requiere de una conexión directa con el mundo tangible y de unos elementos sensibles, mismos que hacen posible que dicha imagen se haga una experiencia colectiva en tanto sus elementos pueden ser percibidos por un gran número de individuos.

Ahora bien, las imágenes icónicas son el resultado de la representación de las experiencias de un individuo al interactuar con un entorno sensible tanto desde el referente como en el momento de generar una modelización. Para ejemplificar esta situación basta con fijarse nuevamente en la figura 1: ya que en el momento de la captura los elementos ambientales generan efectos de carácter estético sobre quien captura y decide cual es el instante a capturar, así como los fenómenos que han de ser descartados en dicho proceso; en el otro lado se encuentra quien lee este texto y jamás ha estado en dicho lugar, pero gracias a esta imagen puede comenzar a configurar un imaginario del espacio en mención. 


\section{Imaginarios y sinestesia}

Se establece entonces que el resultado de los procesos de percepción es una imagen mental, no necesariamente icónica, ya que el resultado es lo que António Damásio (2010) Ilama cartografía mental: una especie de mapa de navegación relacional que pone en conexión estímulos y conceptos devenidos de diversas fuentes. Estas cartografías usan datos que son interpretados por los órganos de la percepción desde orígenes diversos, pero que una vez en el cerebro no poseen una naturaleza definida; esto debido a lo que el neurocientífico Rodolfo Llinás (2002) expone sobre el cerebro cuando lo describe como "máquinas de soñar que construyen modelos virtuales del mundo real" (p. 110), al permanecer en un estado de aislamiento físico y tener la capacidad de reconstruir el mundo externo.

Es precisamente esa indefinición lo que permite generar imágenes mentales a través de las interpretaciones sinestésicas, ya que estas logran completar el sentido de los fenómenos reconstruidos mentalmente —o imágenes mentalesa partir de la asociación de sentidos y significados que parecen no tener relación. Este fenómeno es definido por Rafael Redondo Barba (1991), quien argumenta que existe un proceso de facilitación intersensorial que posibilita a la sinestesia presentarse como: "1. Un enlace asociativo entre varias zonas sensoriales, unidas como si las impresiones de una pasaran a la otra. 2. Un cúmulo de asociaciones de diferente y diversa naturaleza conceptual. 3. Una unificación persistente de sensaciones de distinto origen" (p. 19).

Estas unificaciones en el sentido y construcción de las imágenes mentales permiten a los individuos construir cartografías mentales dotadas de todas las posibilidades disponibles en el mundo sensible; además de otorgar significado a las relaciones gracias a la experiencia que se encarga de variar constantemente los elementos en las reconstrucciones por medio de la confrontación con 
la memoria, en lo que Jorge Larrosa (2006) define como el principio de irrepetibilidad, ya que un nuevo contacto con un fenómeno se encuentra determinado por el anterior y genera la proyección hacia el siguiente.

De otro lado hay que tener en cuenta que en los procesos de coafectación que dan pie a la generación de cartografías mentales no se da una reconstrucción mimética del mundo sensible puesto que aparece lo que el neurocientífico Donald Hoffman (2015) denomina símbolos perceptuales; una lectura relacional de los estímulos, destinada a garantizar ubicuidad en la construcción de conceptos a partir de los datos obtenidos del universo tangible. De este modo es natural que se asocie ciertos colores con niveles de madurez, toxicidad o sabor en un fruto, así como aspectos estructurales de animales con riesgos biológicos.

Ahora bien, se entiende el proceso de generación de cartografías mentales como uno completamente relacionado con la experiencia de los fenómenos tangibles, pero simbolizado a partir de las interpretaciones sinestésicas. Sin embargo, cabe el acercamiento a una noción de lo que existe afuera como un sistema que interrelaciona todos los fenómenos o cosas presentes en una suerte de pluralismo o ausencia de centros como lo define desde la teoría del actor-red Bruno Latour (1999), ya que de forma análoga a las cartografías mentales los elementos del mundo sensible también se encuentran en una constante interacción.

Es por esta razón que hablar de comunicación visual implica hablar del espacio mismo, ya que la visualidad y la construcción de imágenes mentales obedecen a la interacción con el mundo y definen a la vez gran parte de las maneras de comunicarse con el mismo. Entonces el espacio físico se constituye en el escenario para las interacciones y las relaciones entre los fenómenos, elementos materiales e interpretaciones simbólicas; es en sí, el resultado de la constante afectación entre lo imaginado y lo materializado. 
Por todo lo anterior, resulta pertinente para aquellos profesionales dedicados a la configuración de relatos visuales icónicos comprender que las imágenes mentales son cartografías visuales dinámicas o cartografías sinestésicas en las que se proyectan simulaciones del entorno que tienen en cuenta relaciones de causa-efecto, así como valores de signo.

Esta apreciación es corroborada cuando se revisan consideraciones sobre el paisaje planteadas por Adriana Gómez (2012), quien señala acerca de la estructura o elementos definitorios del paisaje que este se trata de la experiencia espaciotemporal de todos los elementos físicos y estímulos que rodean al individuo e interactúan con él a diferentes escalas; así, tanto de manera secuencial como simultánea, hay que tener en cuenta que los estímulos también provienen de las acciones de otros individuos o sistemas presentes.

En ese mismo orden de ideas, la experiencia del ser humano frente al mundo está construida por el intercambio de información entre el cerebro como elemento físicamente aislado y el mundo de los objetos o el mundo material. Pero la significación del segundo también es un proceso de construcción mental en la que se le otorga significado y se determina el tipo de variables que son necesarias en cada interacción dependiendo del tipo de afectación que se busque o de cual sea la intencionalidad frente a las cosas presentes en el espacio.

\section{Lenguaje visual-cultura visual}

El lenguaje visual contribuye a que formemos nuestras ideas sobre cómo es el mundo, ya que a través de él absorbemos y creamos información especial que captamos gracias al sentido de la vista. (Acaso, 2011, p. 22)

María Acaso plantea que a pesar de que los seres humanos hacen uso de sus sistemas perceptuales para leer e interpretar imágenes esta lectura se realiza 
de manera superficial dado que de forma inconsciente se dan interacciones con los fenómenos del mundo, pero existe un alto nivel de analfabetismo visual a la hora de comprender profundamente los mecanismos de lectura y por lo tanto de escritura de las imágenes; bien sean icónicas, como las define Villafañe (1985), o bien sean imágenes mentales pertenecientes al mundo de la construcción mental (Acaso, 2011).

Es importante tener en cuenta que la comunicación visual se fundamenta en la interpretación de representaciones que pretenden copiar los efectos de las condiciones del universo planteadas por Llinás (2002), así como las relaciones del paisaje planteadas por Gómez (2012). Por ello resulta un lenguaje mucho menos abstracto, aunque si más complejo por sus posibilidades relacionales, al tratarse de interpretación de fenómenos y representaciones que están más cerca de los asuntos perceptuales disponibles en el mundo que se reconoce como sensible o tangible.

Sin embargo, la relación de la representación con la realidad se ve alterada en el proceso de modelización icónica (Villafañe, 1985), ya que quien emite una imagen no la construye de la nada; su proceso experiencial y su lugar en el mundo se convierten en elementos mediadores en la iconización.

Por su parte los elementos frente a la experiencia expuestos por Larrosa (2006) plantean que la construcción de discursos visuales está determinada por el principio de singularidad que dicta que cada episodio o encuentro con un mismo fenómeno tendrá un resultado único, ya que cada vez se alimenta de nueva información. Por tanto, cada enfrentamiento con un fenómeno permite reescribir la cartografía mental existente.

A su vez la generación de cartografías mentales determina que la interpretación de un discurso icónico no está limitada a la simple precepción visual, existe 
en el cerebro la capacidad de abstraer la naturaleza de las variables visuales y relacionarlas con otras informaciones o más bien con información proveniente de otras naturalezas, experiencias, voluntades y emociones, lo que se ha denominado interpretación o asociación sinestésica.

\title{
Al respecto, Acaso (2011) plantea:
}

\begin{abstract}
dentro del campo de la semiología de la imagen, representar consiste en sustituir la realidad a través del lenguaje visual. No debemos olvidar que el acto en el que el emisor decide qué representar es realizado en un contexto determinado (en determinado momento, en determinado lugar, por determinados motivos), de manera que el acto de la representación no es neutro: debido a que el autor aporta su experiencia personal, ninguna representación es igual de individuo a individuo. Ya que en el proceso de representación es fundamental la experiencia personal del autor, se puede decir que la representación implica transformación, por lo que la realidad desaparece en el acto de la representación. (p. 33)
\end{abstract}

Es entonces el acto de representación icónica un enunciado mediado por una intencionalidad, unos imaginarios o una interpretación de una cartografía mental. Por otro lado el acto de interpretación también está mediado por las cartografías mentales o los imaginarios dado que lo que se encuentra el lector de una imagen es ese repertorio de elementos que definen la iconicidad de un discurso, pero es él mismo lector quien a partir de sus propios imaginarios realiza una lectura relacional de los componentes de una imagen icónica.

Acaso (2011) diferencia la lectura de elementos de lenguaje visual en dos tipos de discurso: (i) discurso denotativo: mensaje objetivo del signo, nivel físico. Similaridad, ubicuidad, consenso interpretativo, colectivo; (ii) discurso connotativo: mensaje subjetivo del signo, nivel simbólico. Cambia con el contexto y depende del observador.

El primero entendido como los elementos de naturaleza icónica, aquellos correspondientes al mundo de la experiencia sensible: colores, formas, 
representaciones en diferentes niveles de figuración entre otros. En cuanto al discurso connotativo se trata de las capas relacionales más profundas dentro del paisaje determinado por ciertas condiciones culturales en las que las relaciones de la cartografía mental adquieren una naturaleza mucho más abstracta, fundamentada en la interacción de los símbolos perceptuales.

El lenguaje visual permite entonces determinar unas características relacionales y de construcción de imágenes que se comprenden también de manera unificada gracias al proceso perceptual y al proceso de pensamiento; sin embargo, a la luz de todos los elementos evaluados queda claro que, si bien no son todos de orden visual o naturaleza icónica, si son elementales en la configuración de imágenes y en la concreción del sentido de las mismas. Tal y como lo plantea Acaso (2011), una imagen es entonces una unidad de representación visual generada mediante lenguaje visual que sustituye o crea la realidad. Y en este acto de sustitución tiene el potencial de activar relaciones sinestésicas y simbólicas en diferentes interactores gracias a las variables que le permiten conservar su estructura desde el lenguaje visual.

De esta manera el lenguaje visual posibilita la interrelación entre mapas mentales y el mundo tangible debido a la colectivización de los significados y las interpretaciones, permite manifestar los elementos culturales que componen el imaginario icónico de un grupo social o un contexto y genera un escenario de relación entendido como la cultura visual sobre la cual Acaso (2007) propone:

"cultura visual" puede definirse como el conjunto de representaciones visuales que forman el entramado que dota de significado al mundo en el que viven las personas que pertenecen a una sociedad determinada. Es el conjunto de productos visuales que pueblan nuestra cotidianidad y dan origen a la identidad del individuo contemporáneo. Es una de las herramientas que construye el significado de la mente, es decir, el sistema que da sentido a nuestras vidas. (p. 18) 
En este sentido la cultura visual se comprende como una construcción colectiva, una red de afectaciones. Aunque en este caso una fundamentada en los intercambios que se dan entre dos dimensiones, una generada por los elementos del mundo que han de tener unos efectos y unas interpretaciones en otra dimensión que puede ser entendida como la de las imágenes o cartografías mentales. Por último, la cultura visual fundamenta el espacio de encuentro o interfaz entre individuos en el que cada uno manifiesta de una u otra forma sus construcciones mentales por medio de códigos y manifestaciones culturales como el lenguaje visual. La cultura visual es la manifestación tangible y simbolizada de la interacción de características sensibles e interpretativas, significados, formas, colores, emociones, sentidos y lecturas que son compartidas por un grupo que de manera constante se encuentra intercambiando impresiones del mundo para llegar a ciertos acuerdos sobre el sentido otorgado a fenómenos de carácter visual o sinestésico. O como lo define Ricardo Campos (2012):

\begin{abstract}
en resumen, la cultura visual, puede ser entendida, en primer lugar, como un repositorio visual asociado a contextos colectivos particulares, donde determinados lenguajes y signos visuales son elaborados y cambiados; en segundo lugar, como un modo de aprehender y decodificar visualmente la realidad, teniendo en cuenta la naturaleza cultural y psicosocial de la percepción y la cognición; y, en tercer lugar, como un sistema compuesto por un aparato tecnológico, político, simbólico y económico, enmarcado en un horizonte sociocultural e histórico más amplio con el que convive, que ayuda a moldear, tal como es por este configurado. (p. 24)
\end{abstract}

Campos deja claro que la cultura visual es el resultado de las acciones humanas en diferentes dimensiones, manifestada a través de las formas de representar; así como de las formas de ver, interpretar e imaginar; lo que pone a cualquier objeto comunicativo presente en el mundo, directamente en relación con esas dimensiones.

Por tanto, las características necesarias para la lectura del mundo también son susceptibles de convertirse o formar elementos de cultura visual. Esto se ve 
explicado cuando por ejemplo ciertas personas comienzan a tener predilección por algunos colores sobre otros debido a la relación con un equipo de futbol o con un género musical, ya que esa característica empieza a ser asociada en la cartografía mental con un sistema de conceptos.

Finalmente si se tiene en cuenta que una de las principales características del proceso de aprendizaje del diseño de comunicación visual es la fuerte tendencia a la configuración de lenguajes visuales es de pertinencia para los diseñadores de comunicación visual el dominio del análisis de las relaciones entre espacio físico, cartografías mentales, lenguaje visual y cultura visual, ya que existe tanto la necesidad de escribir en un lenguaje adecuado a cada contexto como de interpretar elementos del paisaje para producir mensajes visuales.

\section{Conclusiones}

\section{Cultura visual y diseño de comunicación visual}

Cabe aclarar que el propósito de este texto es generar una reflexión acerca de la pertinencia del uso de herramientas de clasificación de características en procesos de diseño de comunicación visual; para esto es necesario establecer una noción de diseño enmarcada en la esencia de los temas explorados.

César González Ochoa (2015) hace una reflexión acerca del uso del lenguaje para generar conocimiento sobre los hechos del mundo dado que al tratarse de sistemas simbólicos los lenguajes realizan denominaciones abstractas de las cosas, les dan una posición en un sistema, sin embargo, desconocen la experiencia singular que es un fenómeno mucho más rico, aunque paradójicamente no puede ser colectivo. 
El diseño es en sí un camino para la prefiguración de lenguajes —visuales en el caso del diseño de comunicación visual- que busca racionalizar la interacción entre individuos y el entorno a través de la transformación en dos instancias, la física y la mental. Representada la primera en las mediaciones dispuestas en el entorno, la segunda instancia se constituye en la resignificación que puede lograr el diseño aplicado en las cartografías mentales de los individuos entregando nuevos caminos para la interacción; dicho de otra manera, el aprendizaje que puede lograr un usuario cuando se enfrenta a una nueva interfaz o a un nuevo objeto.

Señala González (2015) que la acción es fundamental en las actividades humanas no simplemente aquellas limitadas a suplir necesidades básicas, también aquellas que se encaminan a la construcción de imaginarios políticos y sociales; esto puede estar fundamentado por el papel de la experiencia en la generación de cartografías mentales y por lo tanto generar algo que el autor citado define como pluralismo o una condición que diferencia a todos los seres humanos existentes aun cuando sus acciones generen una colectividad.

Sin embargo, ha de considerarse la acción del diseño una racionalizada en búsqueda de la ubicuidad; y que como acción corresponde a lógicas de la producción industrial o iterativa. Pero la racionalización de la acción buscada por el diseño como actividad proyectual no puede escapar a las interpretaciones de carácter simbólico en la medida en que las mediaciones u objetos producidos entran a formar parte activa dentro del paisaje y por lo tanto configuran elementos de la cultura visual; además de estar compuestos o escritos en elementos de lenguaje visual, específicamente aquellos objetos comunicativos -imágenes icónicas-.

En este sentido es coherente que el diseñador en su búsqueda de racionalización logre comprender relaciones intrincadas más allá de la simple formalización y 
que pueda hacerlo mediante herramientas replicables, revisables y enseñables -en otras palabras, instrumentos-.

Por su parte William Ospina Toro (2016) permite justificar desde sus reflexiones la necesidad de que los métodos de diseño valoren las relaciones de los conceptos y los elementos constitutivos de la cultura visual a la hora de establecer categorizaciones para representaciones visuales-objetuales, ya que como se ha comprendido las intrincadas relaciones de la cultura visual se fundamentan en relaciones complejas que transforman constantemente los significados.

Ospina (2016) plantea, con relación a las dinámicas del entorno y la mirada del diseño, desde el método, que:

\footnotetext{
bajo esta perspectiva, la noción de problema en el diseño pasa a ser considerado como una situación abierta, esto es, atiende a una dimensión social que obliga al diseñador a trabajar con los conjuntos de significados emanados del contexto y lo sitúa en medio de tal conjunto, para articular los significados y, en segunda instancia, generar artefactos (Jahnke, 2012), de tal forma que al ampliar la búsqueda inicial de los hechos anteriores y exteriores al artefacto, hechos que constituyen el contexto diseño -industriales, sociales, económicos, estéticos, políticos- y que se ven adscritos a la entidad propia del diseño (Llovet, 1981), se hace necesaria su interpretación para reconocerlos en la situación de partida, interpretación que llena de significados el intercambio de conceptos entre los rasgos que se hacen pertinentes y el diseñador que los organiza mediante el método en diseño. (p. 66)
}

Por ello se tiene que el diseño es una disciplina que racionaliza los procesos de construcción de imágenes mentales, que también tienen una finalidad proyectiva, con el fin de establecer mediaciones que han de adaptarse a condiciones particulares dentro del paisaje — para este caso las visuales-. Ha de ser el diseño una disciplina eficiente al analizar sistemas complejos si quiere cumplir con el objetivo de generar objetos capaces de insertarse dentro de la cultura visual de manera activa y susceptible de generar cambios en los imaginarios y la significación de los mismos. 
El diseño de comunicación visual requiere de la revisión de métodos e instrumentos de recolección, clasificación y abstracción de variables que le permitan generar una proyección racional y tangible de las cartografías mentales que están en relación con el entorno; teniendo en cuenta que la afectación entre el mundo simbólico, las mediaciones tecnológicas y el paisaje es un proceso constante sin fin donde la significación y las relaciones se encuentran en un estado caracterizado por una altísima flexibilidad conceptual. Por consiguiente, el diseñador de comunicación visual —como personaje validado institucionalmente para la producción de imágenes icónicas- debe revisar su acción y proyectarla hacia el ejercicio y la ejecución de instrumentos, técnicas y métodos de análisis de la complejidad de la visualidad, matizada por las interpretaciones sinestésicas. Deberá adoptar y adaptar elementos devenidos de la antropología visual con miras a establecer un ejercicio etnográfico de la visualidad que le permita comprender a fondo las ramificaciones y relaciones que se desprenden de las variables empleadas tanto en la observación como en la síntesis de discursos visuales.

\section{Referencias}

Acaso, M. (2007). Esto no son las torres gemelas, cómo aprender a leer la televisión y otras imágenes. Madrid, España: CATARATA.

Acaso, M. (2011). El lenguaje visual. Barcelona, España: Paidós.

Campos, R. (2012). A cultura visual e o olhar antropológico. VISUALIDADES, $10(1), 17-37$.

Damasio, A. (2010). Y el cerebro creó al hombre. Barcelona, España: Ediciones Destino S.A.

Gómez, A. (2012). Criterios metodológicos para el análisis de la calidad visual del paisaje urbano y su sostenibilidad. Bogotá, Colombia: Universidad Santo Tomás. 
González Ochoa, C. (2015). El diseño como acción. Manizales, Colombia: Universidad de Caldas.

Hoffman, D. (11 de 6 de 2015). Do we see reality as it is? Recuperado de https://www.youtube.com/watch?v=oYp5XuGYqqY.

Larossa, J. (2006). Sobre la experiencia. Separata Revista Educación y Pedagogía, $18,43-67$.

Latour, B. (1999). Technology Is Society Made Durable. The Sociological Review, 38 (51), 103-131.

Llinás, R. (2002). El cerebro y el mito del yo. Bogotá, Colombia: Norma.

Ospina, W. (2016). El método en diseño como expresión de producción de conocimiento. Revista KEPES, 13 (13), 51-71.

Redondo Barba, R. (1991). Un extraño fenómeno perceptivo: la sinestesia. Revista Internacional de los Estudios Vascos, 36 (1).

Villafañe, J. (1985). Introducción a la teoría de la imagen. Madrid, España: Ediciones Pirámide.

Wong, W. (1991). Fundamentos del diseño bi- y tri-dimensional. Barcelona, España: Gustavo Gili.

Como citar: López, J.A. (2019). Visualidad y diseño de comunicación visual, relación cartografías mentalesentorno en la definición de variables de diseño de comunicación visual. Revista KEPES, 16 (19), 277-293. DOI: 10.17151/kepes.2019.16.19.11 